We performed a multivariate analysis that showed that being overweight and presenting a waist / hip index above $0.90 \mathrm{~cm}$ confers an increased risk of developing PsA (Table 2).

Table 2. Multivariate analysis of significant clinical risk factors for PsA.

\begin{tabular}{lcc}
\hline Variable & $p$ & OR (95\% Cl) \\
\hline Hypertension & 0.239 & $1.69(0.70-4.05)$ \\
Overweight & 0.027 & $2.57(1.11-5.92)$ \\
Waist/hip index $>0.90$ & 0.007 & $2.80(1.32-5.95)$ \\
\hline
\end{tabular}

Conclusion: Several traditional cardiovascular risk factors were found with a higher prevalence in the group with psoriasis. It is critical that physicians known the common comorbidities associated with PsA so that they can provide optimal management and treatment and improve mortality and quality of life.

References:

[1] Husni, M. E. (2015). Comorbidities in psoriatic arthritis. Rheumatic Disease Clinics, 41(4), 677-698

Disclosure of Interests: None declared

DOI: 10.1136/annrheumdis-2020-eular.6008

\section{AB0817 DOES SMOKING AFFECT SECUKINUMAB TREATMENT OUTCOMES AND SAFETY IN PATIENTS WITH PSORIATIC ARTHRITIS? - REAL WORLD DATA FROM THE GERMAN AQUILA STUDY}

E. Riechers ${ }^{1}$, U. Kiltz ${ }^{2}$, J. Brandt-Juergens ${ }^{3}$, P. Kästner ${ }^{4}$, D. Peterlik ${ }^{5}$, H. P. Tony ${ }^{6}$ on behalf of the AQUILA Study Group. ${ }^{1}$ Medizinische Hochschule Hannover, Clinic for Immunology and Rheumatology, Hannover, Germany; ${ }^{2}$ Rheumazentrum Ruhrgebiet, Herne and Ruhr-University Bochum, Herne, Germany; ${ }^{3}$ Rheumatologische Schwerpunktpraxis, Berlin, Germany; ${ }^{4}$ Ambulantes Rheumazentrum, Erfurt, Germany; ${ }^{5}$ Novartis Pharma GmbH, Immunology, Hepatology \& Dermatology, Nürnberg, Germany; ${ }^{6}$ Universitätsklinik, Rheumatology/ Immunology, Würzburg, Germany

Background: Several studies have shown a negative association between smoking status and psoriatic arthritis (PsA) clinical outcomes. ${ }^{1,2}$ The German non-interventional study AQUILA provides real-world data on the influence of smoking on therapeutic effectiveness and safety issues under secukinumab (SEC), a fully human monoclonal antibody that selectively inhibits interleukin-17A

Objectives: The aim of this interim analysis is to describe selected baseline (BL) demographics, to evaluate SEC effectiveness on disease activity and depressive mood and to report the safety profile depending on smoking status of PsA patients.

Methods: AQUILA is an ongoing, multi-center study including up to 2700 patients with active PsA or ankylosing spondylitis. Patients were observed from BL up to week (w) 52. Real-world data was assessed prospectively and analyzed as observed. In addition to the assessment of C-reactive protein (CRP), data was collected on patient's disease activity (tender/swollen joint counts, TJC/SJC), skin disease activity (Psoriasis Area and Severity Index, PASI) and depressive mood (Beck's Depression Inventory version II, BDI-II). For calculation of the proportion of patients who experienced (serious) adverse events ((S)AEs), all PsA patients were included who received at least one dose of SEC irrespective of further documentation of any study visit. This interim analysis focuses on subgroups non-smoker (NS) and smoker (S).

Results: At BL, 641 PsA patients were included: $49.8 \%(n=319)$ non-smokers (NS) and $24.3 \%(n=156)$ smokers $(S) .17 .5 \%(n=112)$ were ex-smoker and $8.4 \%(n=54)$ of unknown smoking status. In both, NS and $S$, the proportion of women was higher (58.0\% in NS and $67.3 \%$ in S). NS were slightly older than $S$ (mean age: $53.8 / 49.7$ years). There were no significant differences between NS and $S$ in mean CRP within the 52 weeks (Fig. 1A). Both TJC and SJC improved over time and were similar between NS and S (Fig. 1B). Although mean absolute PASI value was worse in $\mathrm{S}$ at $\mathrm{BL}$, a similar temporal improvement was seen in both groups (NS: 7.0 at BL to 1.0 at w52; S: 9.2 at $\mathrm{BL}$ to 1.0 at w52). BDI-II scores decreased in both groups with overall higher values in S (NS: 10.9 at BL to 9.1 at w52; S: 12.8 at $B L$ and 10.8 at w52). Regarding the occurrence of AEs and SAEs with or without suspected relationship to SEC, NS had percentagewise less events than $S$ (Table 1). In addition, percentage of PSA patients who discontinued SEC treatment due to an $\mathrm{AE}$ was lower for NS compared to $\mathrm{S}$.
Table 1. Overview of AEs (and SAEs) under SEC treatment depending on smoking status in PsA patients

\begin{tabular}{lccc}
\hline Number of patients with & NS (N=333), n (\%) & $\mathbf{S}(\mathbf{N}=161), \mathbf{n}(\%)$ & P value \\
\hline AE & $233(70.0)$ & $118(73.3)$ & 0.11 \\
AE with suspected relationship to SEC & $129(38.7)$ & $72(44.7)$ & 0.10 \\
SAE & $74(22.2)$ & $45(28.0)$ & 0.06 \\
SAE with suspected relationship to SEC & $29(8.7)$ & $18(11.2)$ & 0.37 \\
\hline
\end{tabular}
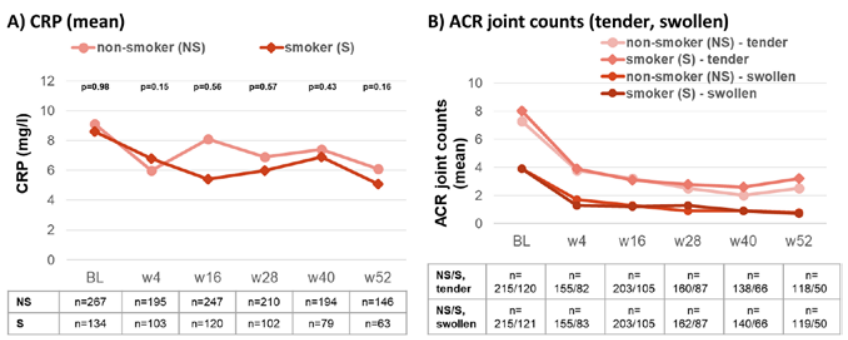

Figure 1. Disease activity in PSA patients treated with SEC depending on the smoking status ${ }^{{ }^{*}} \mathrm{CRP}$ data/ACR joint counts were documented not for all PsA patients at $\mathrm{BL}$ and subsequent visits.

Conclusion: In a real-world setting, SEC improved disease activity and depressive mood of PsA patients with no obvious differences between NS and S. Overall, this interim analysis shows that SEC is an effective and reliable treatment, irrespective of the PsA patients' smoking status. Further progress of the AQUILA study as well as long-term data from other real-world observational studies with SEC, such as SERENA, will reveal whether this trend will continue.

References:

[1] Hojgaard P et al, Ann Rheum Dis 2015; 74:2130-6; 2. Eder L et al, Arthritis Care Res 2011 Aug; 63:1091-7

Disclosure of Interests: Elke Riechers Grant/research support from: AbbVie, Chugai, Lilly, Janssen, Novartis, Pfizer, Roche, UCB, Consultant of: AbbVie, Chugai, Novartis, UCB, Uta Kiltz Grant/research support from: AbbVie, Amgen, Biogen, Novartis, Pfizer, Consultant of: AbbVie, Biocad, Eli Lilly and Company, Grünenthal, Janssen, Novartis, Pfizer, UCB, Speakers bureau: AbbVie, MSD Novartis, Pfizer, Roche, UCB, Jan Brandt-Juergens: None declared, Peter Kästner Consultant of: Chugai, Novartis, Daniel Peterlik Employee of: Novartis Pharma $\mathrm{GmbH}$, Hans-Peter Tony Consultant of: AbbVie, Astra-Zeneca, BMS, Chugai, Janssen, Lilly, MSD, Novartis, Pfizer, Roche, Sanofi DOI: 10.1136/annrheumdis-2020-eular.365

\begin{tabular}{|l|l|}
\hline AB0818 & SKIN INVOLVEMENT IN PSORIATIC ARTHRITIS \\
& (PSA) - THE INCREMENTAL IMPACT OF PSORIASIS \\
& ON QUALITY OF LIFE, DISABILITY AND WORK \\
& PRODUCTIVITY: REAL-WORLD SURVEY IN US AND \\
& EUROPE
\end{tabular}

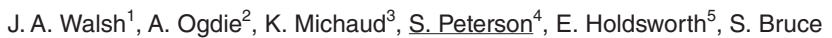
Wirta $^{6}$, S. Meakin ${ }^{5}$, S. D. Chakravarty ${ }^{7}$, A. Schubert ${ }^{8}$, L. Gossec ${ }^{9} .{ }^{1}$ University of Utah, Salt Lake City, United States of America; ${ }^{2}$ Perelman School of Medicine, Penn Medicine, Philadelphia, United States of America; ${ }^{3}$ University of Nebraska Medical Center, Omaha, United States of America; ${ }^{4}$ Janssen Global Services, LLC, Horsham, United States of America; ${ }^{5}$ Adelphi Real World, Bollington, United Kingdom; ${ }^{6}$ Janssen-Cilag, Solna, Sweden; ${ }^{7}$ Janssen Scientific Affairs, LLC/Drexel University College of Medicine, Horsham, United States of America; ${ }^{8}$ Janssen-Cilag, Warsaw, Poland; ${ }^{9}$ Sorbonne Universite, Paris, France

Background: PsA involves joint and skin symptom presentation that varies across patients. Differences in patients outcomes with joint only, and joint and skin involvement have not been extensively studied in a real-world setting.

Objectives: To assess prevalence of joint only, and joint and skin disease in a real-world clinical setting, and to assess incremental impact of skin symptoms on quality of life (QoL), disability and work productivity.

Methods: A cross-sectional survey in patients with PsA recruited by rheumatologists and dermatologists was conducted in France, Germany, Italy, Spain, UK and US. Data were collected Jun-Aug 2018 via physician-completed patient record forms and patient self-completed forms. Patients were compared by joint and skin involvement using parametric and non-parametric tests. Multiple linear regression analyses examined impact of incremental body surface area (BSA) on patient reported outcomes (PROs). Models controlled for gender, age, time 
since diagnosis, employment status, biologic DMARD use, BMI, number of joints affected.

Results: Of 1,909 patients (539 US, 1,370 EU), 35\% of patients had joint only disease, while $26 \%, 23 \%$, and $16 \%$ experienced joint disease plus $1-3 \%$, >3$10 \%$, and $>10 \%$ BSA respectively (Figure 1 ). Patients were comparable demographically (Table 1). After controlling for demographics and number of joints involved, results showed BSA independently and significantly impacted QoL, work productivity, disability (Table 2).

Table 1. Comparison of patient demographic and disease characteristics by joint and skin disease involvement

\begin{tabular}{|c|c|c|c|c|c|}
\hline & $\begin{array}{l}\text { Joints only } \\
(n=673)\end{array}$ & $\begin{array}{c}1-3 \% \\
(n=493)\end{array}$ & $\begin{array}{l}>3-10 \% \\
(n=447)\end{array}$ & $\begin{array}{c}>10 \% \\
(n=296)\end{array}$ & p-value \\
\hline Age, mean (SD) & $49.2(13.7)$ & $49.2(13.2)$ & $47.6(12.4)$ & 47.6 & 0.09 \\
\hline Male, $n(\%)$ & 379 (56.3) & $260(52.7)$ & $248(55.5)$ & 155 (52.4) & 0.53 \\
\hline BMI, mean (SD) & $26.9(4.9)$ & $26.8(4.6)$ & $26.7(4.2)$ & $26.5(4.7)$ & 0.52 \\
\hline Caucasian, $\mathrm{n}(\%)$ & $621(92.3)$ & $442(89.7)$ & $399(89.3)$ & 270 (91.2) & 0.41 \\
\hline Full-time employment, n (\%) & $391(60.9)$ & $275(57.7)$ & $259(59.1)$ & $153(53.1)$ & 0.01 \\
\hline Biologic tx, n (\%) & $420(62.4)$ & $283(57.4)$ & $218(48.8)$ & $141(47.6)$ & $<0.01$ \\
\hline Months since diagnosis, mean (SD) & $68.4(76.2)$ & $56.7(68.2)$ & $54.2(67.3)$ & $52.1(75.1)$ & ) $<0.01$ \\
\hline Current BSA \%, mean (SD) & 0.0 & $1.7(0.8)$ & $6.3(2.0)$ & $21.3(10.1)$ & $<0.01$ \\
\hline *66 swollen joint count, mean (SD) & $1.5(3.6)$ & $2.1(4.2)$ & $7.1(11.1)$ & $6.9(10.5)$ & $<0.01$ \\
\hline${ }^{*} 68$ tender joint count, mean (SD) & $2.1(4.1)$ & $3.7(6.4)$ & $6.0(7.7)$ & $9.8(10.0)$ & $<0.01$ \\
\hline
\end{tabular}

${ }^{*}$ Calculated on available data, $\mathrm{n}=394$

Table 2. Incremental impact of BSA on PROs

\begin{tabular}{lccc}
\hline & $\begin{array}{c}\text { BSA in addition to } \\
\text { joint involvement }\end{array}$ & $\begin{array}{c}\text { Change in predicted } \\
\text { PRO values }\end{array}$ & P value \\
\hline EQ5D utility ( $n=656)$ & Joint only (ref) & 0.85 & \\
& $1-3 \%$ & -0.02 & 0.31 \\
& $>3-10 \%$ & -0.06 & $<0.01$ \\
EQ5D VAS ( $\mathrm{n}=668)$ & $>10 \%$ & -0.06 & $<0.01$ \\
& Joint only & 78.14 & 0.74 \\
& $1-3 \%$ & -0.58 & 0.03 \\
WPAI \% overall work impairment $(\mathrm{n}=369)$ & $>3-10 \%$ & -3.78 & 0.14 \\
& $>10 \%$ & -3.04 & \\
& Joint only & 15.88 & 0.91 \\
& $1-3 \%$ & +0.32 & $<0.05$ \\
HAQ-DI ( $\mathrm{n}=635)$ & $>3-10 \%$ & +5.11 & 0.01 \\
& $>10 \%$ & +7.51 & \\
& Joint only & 0.32 & 0.41 \\
& $1-3 \%$ & +0.04 & $<0.01$ \\
PsAID12 ( $\mathrm{n}=642)$ & $>3-10 \%$ & +0.22 & $<0.01$ \\
& $>10 \%$ & +0.27 & \\
& Joint only & 1.66 & 0.03 \\
& $1-3 \%$ & +0.42 & $<0.01$ \\
& $>3-10 \%$ & +1.22 & $<0.01$ \\
& $>10 \%$ & +1.37 &
\end{tabular}

a PRO key for worse outcome (range): EQ5D utility (0-1.0) = lower; EQ5D VAS $(1-100)=$ lower; WPAI $(0-100)=$ higher; HAQ-DI $(0-3)=$ higher; PsAID12 $(0-10)=$ higher

Figure 1: Prevalence of joint and skin involvement across regions

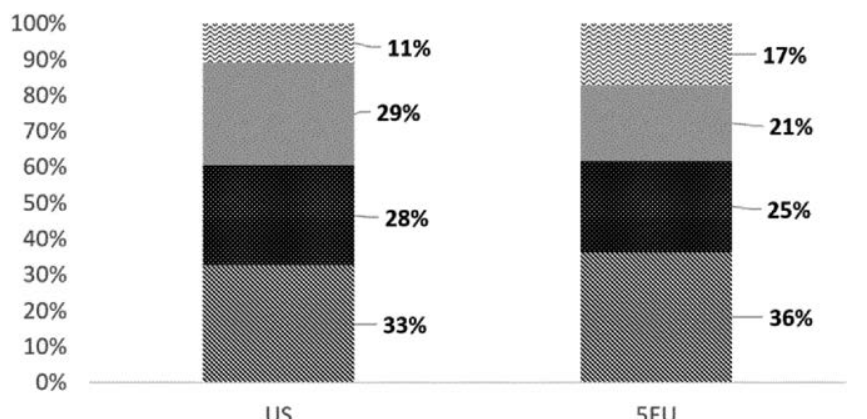

US

$5 E U$

\section{Joints Only BSA $1-3 \%$ BSA $>3 \%-10 \% \approx B S A>10 \%$}

Conclusion: Two thirds of this sample of actively treated PsA patients have skin involvement. Over half would be considered moderate-severe (BSA $>3 \%$ ). After controlling for joint symptoms, results show that increasing skin involvement in PsA patients adversely impacts QoL, disability and work productivity.

Disclosure of Interests: Jessica A. Walsh Grant/research support from: AbbVie, Pfizer, Janssen, Consultant of: AbbVie, Novartis, Eli Lilly and Company, UCB, Alexis Ogdie Grant/research support from: Pfizer to Penn,
Novartis to Penn, Amgen to Forward/NDB, Consultant of: Abbvie, Amgen, Bristol-Myers Squibb, Celgene, Corrona, Janssen, Eli Lilly, Novartis, Pfizer, Kaleb Michaud Grant/research support from: Janssen, Steve Peterson Employee of: Janssen Research \& Development, LLC, Elizabeth Holdsworth Employee of: Adelphi Real World, Sara Bruce Wirta Employee of: Jans sen-Cilag Sweden AB, Sophie Meakin Employee of: Adelphi Real World, Soumya D Chakravarty Shareholder of: Johnson \& Johnson, Employee of: Janssen Scientific Affairs, LLC, Agata Schubert Employee of: Janssen-Cilag, Laure Gossec Grant/research support from: Lilly, Mylan, Pfizer, Sandoz, Consultant of: AbbVie, Amgen, Biogen, Celgene, Janssen, Lilly, Novartis, Pfizer, Sandoz, Sanofi-Aventis, UCB

DOI: 10.1136/annrheumdis-2020-eular.5758

\section{$\mathrm{AB} 0819$ \\ FLARES AMONG PATIENTS WITH PSORIATIC ARTHRITIS (PSA) - FREQUENCY AND IMPACT ON PATIENT OUTCOMES: REAL-WORLD SURVEY INTHE US AND EUROPE}

A. M. Orbai ${ }^{1}$, W. Tillett ${ }^{2}$, S. Grieb ${ }^{1}$, S. Peterson ${ }^{3}$, E. Holdsworth ${ }^{4}$ S. Meakin ${ }^{4}$, S. Bruce Wirta ${ }^{5}$, S. D. Chakravarty ${ }^{6}$, L. Gossec ${ }^{7} .{ }^{1}$ Johns Hopkins U School of Medicine, Baltimore, United States of America; ${ }^{2} U$ of Bath, Combe Park, United Kingdom; ${ }^{3}$ Janssen Global Services, LLC, Horsham, United States of America; ${ }^{4}$ Adelphi Real World, Bollington, United

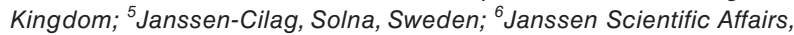
LLC/Drexel U College of Medicine, Horsham, United States of America;

${ }^{7}$ Sorbonne U, Paris, France

Background: Flares in PsA, presenting as periods of acute disease activity, are thought to negatively impact patients' lives. This has not been extensively studied in a real-world setting.

Objectives: Describe flares, assess impact on quality of life and work productivity, and explore predictors.

Methods: A cross-sectional survey among patients with PsA recruited by rheumatologists and dermatologists was conducted in France, Germany, Italy, Spain, UK and US. Data were collected Jun-Aug 2018 via patient record forms and patient self-complete forms. Physicians recorded flare status (in flare currently/flared in last $12 \mathrm{mo} /$ longer than $12 \mathrm{mo}$ or never), demographics, physician perceived severity and clinical outcomes. Patients reported quality of life [QoL] (EQ5D-5L), work productivity (WPAI), disability (HAQ-DI), pain (PsAID12 pain scale). Patients were compared by flare status using parametric or non-parametric tests. Logistic regression explored predictors of flare. Multivariate regression explored the impact of flare status on patient reported outcomes (PRO). The model was adjusted for gender, age, BMI, physician speciality.

Results: Data were collected for 2,238 patients (586 US, 1,652 EU). Mean age was 48.7 years (13.2 SD), $53.8 \%$ were male. Physicians reported $7.5 \%$ were currently in flare and $22.0 \%$ had flared in the last 12 mo. Patients had experienced 2.2 mean flares in the last 12 mo (4.9 SD), lasting a mean 16.4 days (16.2 SD). Patients in flare were comparable demographically with those not; however, those in flare were less likely to work full time ( 43.6 vs. $59.3 \%, p<0.01)$. Patients not in flare had clinically active disease (Table 1 ).

Table 1. Clinical characteristics of patients by flare status

\begin{tabular}{|c|c|c|c|c|}
\hline & $\begin{array}{l}\text { Currently in } \\
\text { flare }(n=168)\end{array}$ & $\begin{array}{c}\text { Flared in last } \\
12 \text { mo } \\
(n=492)\end{array}$ & $\begin{array}{c}\text { Not flared in last } \\
12 \text { mo/never } \\
\text { flared } \\
(n=1578)\end{array}$ & p-value \\
\hline In remission, n (\%) & $4(2.4)$ & $157(33.2)$ & 799 (53.5) & $<0.01$ \\
\hline${ }^{*}$ Current BSA affected, mean (SD) & $10.3(12.0)$ & $6.5(7.6)$ & $5.0(7.7)$ & $<0.01$ \\
\hline *66 SJC, mean (SD) & $5.4(4.6)$ & $4.5(7.3)$ & $2.4(6.9)$ & $<0.01$ \\
\hline *68 TJC, mean (SD) & $7.8(5.8)$ & $5.5(8.3)$ & $3.1(5.6)$ & $<0.01$ \\
\hline \multicolumn{5}{|l|}{ Physician-perceived severity, $n(\%)$} \\
\hline Mild & $35(20.8)$ & $346(70.3)$ & $1297(82.2)$ & $<0.01$ \\
\hline Moderate & $101(60.1)$ & $139(28.3)$ & $261(16.5)$ & \\
\hline Severe & $32(19.0)$ & $7(1.4)$ & $20(1.3)$ & \\
\hline
\end{tabular}

${ }^{*}$ Calculated on available data: Total base sizes: $B S A=1665 ; \quad S J C=514 ; \quad T J C=493$ Satisfaction $=931$

Results showed that flare status significantly impacted QoL, work productivity, disability, and pain (Table 2). Exploring predictors of flare in the last 12 mo in un-adjusted analyses showed that demographic characteristics were not predictive of flare status, however patients presenting as moderate or severe at diagnosis were at greater risk of flare. Patients who were prescribed a bDMARD at diagnosis were at lower risk (Figure 1). 